\title{
Brigitte STUDER, 1968 und die Formung des
}

feministischen Subjekts

Vienne, Picus Verlag, 2011 (Wiener Vorlesungen im Rathaus 153), 56 p.

\section{Régis Schlagdenhauffen}

\section{(2) OpenEdition}

Journals

Édition électronique

URL : http://journals.openedition.org/clio/10915

DOI : $10.4000 /$ clio. 10915

ISSN : 1777-5299

Éditeur

Belin

Édition imprimée

Date de publication : 31 décembre 2012

ISSN : 1252-7017

Référence électronique

Régis Schlagdenhauffen, «Brigitte studer, 1968 und die Formung des feministischen Subjekts », Clio. Femmes, Genre, Histoire [En ligne], 36 | 2012, mis en ligne le 19 avril 2013, consulté le 22 septembre 2020. URL : http://journals.openedition.org/clio/10915; DOI : https://doi.org/10.4000/clio.10915

Ce document a été généré automatiquement le 22 septembre 2020.

Tous droits réservés 


\title{
Brigitte STUDER, 1968 und die Formung des feministischen Subjekts
}

Vienne, Picus Verlag, 2011 (Wiener Vorlesungen im Rathaus 153), 56 p.

\author{
Régis Schlagdenhauffen
}

\section{RÉFÉRENCE}

Brigitte STUDER, 1968 und die Formung des feministischen Subjekts, Vienne, Picus Verlag, 2011 (Wiener Vorlesungen im Rathaus 153), 56 p.

1 Quelles relations entretiennent les mouvements sociaux de 1968 et les mouvements féministes en Europe et en Amérique du Nord? Telle est la question posée dans cet essai par Brigitte Studer, professeure d'histoire suisse et d'histoire moderne à l'Université de Berne. Cependant, ce ne sont pas tant les aspects théoriques - bien qu'il soit difficile d'en faire l'économie - qui sont au cœur de son propos mais bien la constitution d'une puissance agissante qui est au centre du questionnement de l'historienne. Dès l'introduction, elle nous rappelle que dans le contexte de 1968 année qui marque l'apogée d'un continuum de revendications couvrant toutes les années 1960 - les protagonistes avaient un objectif primordial qui comportait lui-même deux facettes : renverser toutes les normes dominantes et redéfinir le vivre ensemble. Cependant, il persiste un seul domaine dans lequel les normes et les valeurs n'ont pas réellement été renversées : celui des rapports sociaux de sexe. En effet, le patriarcat fut certes abondamment critiqué mais il est impossible d'affirmer qu'il fut renversé (preuve en est aujourd'hui).

2 Partant de ce constat, Studer propose de revenir dans la première partie de son ouvrage sur la constitution d'un mouvement féministe transnational et sur ses liens avec la nouvelle gauche. Dans le cadre de cette entreprise de reconstitution de la genèse de ce qu'il convient d'appeler le moment féministe de 1968, l'auteure propose une démarche qui s'appuie sur des témoignages (autobiographiques) de militantes et 
d'intellectuelles de l'époque, tout en faisant appel aux outils de la sociologie des mouvements sociaux et de manière plus limitée à la sociologie interactionniste.

3 La question qui se pose dès lors est la suivante: pourquoi le mouvement féministe n'est-il pas parvenu à renverser le patriarcat? Selon Studer, une première explication réside dans le manque de ressources dont disposaient justement les militantes féministes de l'époque. Que ce soit en Europe ou en Amérique du Nord, l'armature théorique à leur disposition pouvait non pas leur permettre de renverser le patriarcat en tant que tel mais uniquement de constater et de contester l'étendue de son pouvoir. La subtilité et les frontières imposées par cette nuance ne sont pas développées plus longuement (peut-être parce que ce texte est la version écrite d'une conférence donnée en mai 2010 à Vienne). Une seconde explication réside dans les relations paradoxales qu'entretenait le féminisme de la deuxième vague avec la nouvelle gauche. Selon Studer, cette dernière ne tenait pas compte de la puissance des normes dominantes en matière de rapports sociaux de sexes. Aussi est-ce l'absence de relais au sein de la nouvelle gauche qui a conduit les militantes féministes à prendre de la distance vis-àvis de celle-ci.

4 Après avoir procédé à la délimitation du contexte, Studer rappelle que l'un des champs d'investigation de la sociologie des mouvements sociaux est celui de la naissance d'un collectif, d'un «nous». Pour paraphraser James Scott ${ }^{1}$, la question qui se pose est de savoir par quels moyens les militantes sont parvenues à se défaire des public transcripts (c'est-à-dire des normes dominantes) pour mettre en avant des hidden transcripts autrement dit des normes et valeurs propres au groupe opprimé (et qui ne sont pas vues par les dominants). Qu'en est-il de ces hidden transcripts, puisque c'est leur publicisation qui permet aux membres d'un groupe opprimé de prendre conscience de leur communauté de statut?

5 C'est à partir des récits de militantes que Studer entreprend d'en analyser le développement. Qu'il s'agisse des militantes européennes ou états-uniennes, toutes ont en effet pour point commun de partager une communauté d'appuis théoriques qui ont offert autant d'orientations cognitives au féminisme de la deuxième vague. Afin de mieux circonscrire le processus de subjectivation amorcé, c'est du côté de celui de l'engagement militant que Studer poursuit son enquête. Chaque contexte étant unique, Studer recourt à Dominique Memmi et à la " crise de la domination rapprochée $»^{2}$ pour appréhender plus globalement ce processus à travers la réappropriation de leur corps par les femmes.

6 Une illustration de cette entreprise (et des limites qu'elle a connues) réside justement dans la mini-jupe, popularisée par Mary Quant au milieu des années soixante ${ }^{3}$. En effet, la libération des femmes buttait contre les normes traditionnelles, les public transcripts. La question de la réappropriation du corps est ensuite reliée au processus d'appropriation critique de la pensée d'auteurs tels que Gramsci, Fanon ou encore Simone de Beauvoir. Selon Studer, c'est ce phénomène qui permet entre autres de comprendre pourquoi certaines féministes de la deuxième vague ont choisi d'orienter leur engagement militant vers une lutte des sexes.

7 Cependant la lutte des sexes impliquait un second défi qu'il s'est agi de relever dans le cadre de la constitution du sujet féministe: se libérer de la tyrannie de la biologie reproductrice. Il s'agissait dès lors d'inventer un nouveau modèle, en refusant celui de mère, jusqu'alors incarnation du féminin. Selon Luisa Passerini, c'est ainsi que le modèle de la femme de 1968 est nét. C'est donc la prise de conscience de leur propre 
condition et l'expérience de l'oppression qui offrirent les bases de l'engagement de chacune des participantes et permirent leur transformation en sujets politiques agissants. En effet, la vie de chaque femme était certes singulière mais l'expérience de l'oppression commune à toutes.

8 Forte de ce constat, Studer souligne que les apports de l'interactionnisme symbolique nous permettent de saisir que la subjectivité émerge de l'intersubjectivité - ce qui a été mis en œuvre par les militantes au moyen de la " prise de parole » au sein de groupes de discussion. À chaque réunion, les membres des groupes de parole discutaient collectivement d'un sujet et c'est grâce à la collectivisation de la discussion qu'elles sont parvenues à faire émerger au sein de l'agenda politique de nouvelles questions, à radicaliser l'idée que le privé est politique.

9 En conclusion, l'ouvrage, bien que trop court pour aborder en profondeur la complexité des relations entre la nouvelle gauche et le féminisme de la deuxième vague, offre une vision d'ensemble sur la dimension transatlantique de cette dynamique militante.

\section{NOTES}

1. James Scott, La Domination et les arts de la résistance. Fragments d'un discours subalterne, Paris, Éditions Amsterdam, 2009.

2. Cf. Dominique Memmi, Mai-Juin 68, Paris, Éditions de l'Atelier, 2008.

3. Cf. Christine Bard, Ce que soulève la jupe. Identités, transgressions, résistances, Paris, Autrement, 2010.

4. Luisa Passerini, Autobiography of a Generation: Italy, 1968, Hanover, Wesleyan University Press, 1996.

\section{AUTEURS}

\section{RÉGIS SCHLAGDENHAUFFEN}

EHESS- IRIS 